\title{
Hidatidosis de Fosa Renal
}

El quiste hidatídico $(\mathrm{OH})$ se ubica rara vez en el riñón. Esta localización suele ser única, primitiva (1) y de difícil diagnóstico. En series importantes de adultos, el riñón se compromete en $2,2 \%$, (2) frecuencia similar a lo que sucede en niños (Tabla No 1). $(3,4,5)$.

Tabla N: 1

QUISTE HIDATIDICO EN NINOS

Incidencia Quiste Hidatidico Renal

$\begin{array}{llll}\text { 1948-1963 }^{3} 40 \text { casos } & 1 \text { QH Renal } & 2,5 \% \\ \text { Calvo Mackenna } & & \\ 1941-1965^{4} & 144 \text { casos } & 3 \mathrm{QH} \text { Renal } & 2,08 \% \\ \begin{array}{l}\text { Roberto del Río } \\ \text { 1965.1971.5 }\end{array} 48 \text { casos } & 1 \mathrm{QH} \text { Renal } & 2,08 \% \\ \text { Unit. Ped. Marseille } & & \end{array}$

Nos ha llamado la atención que en los últimos 21 meses se han operado 5 hidatidosis de fosa renal y solamente 13 pulmonares y 7 hepáticos. Esta serie clínica nos ha dejado alguna experiencia que deseamos comunicar.

\section{MATERIAL}

Se trata de 5 casos operados en el Servicio de Cirugía del Hospital Luis Calvo Mackenna, 4 niños y una niña, con edades de 4 a 14 años. Cuatro de procedencia urbana $\mathrm{y}$ uno

\footnotetext{
*Servicio de Cirugía, Hospital Luis Calvo Mac-
kenna.

*Servicio de Cirugía, Hospital Luis Calvo Mac-
kenna.
}

Rev. Chilena de Pediatria, Vol. 47, No 2, 1976
Drs. J. Eduardo Caamaño M." y César Izzo s."

rural (comunidad indígena), El antecedente de contacto con perros se menciona en 2 casos.

\section{RESULTADOS}

En la Tabla No 2 se resumen los hechos principales registrados en la ficha clínica de cada caso.

En todos los niños se descubrió una ma. sa palpable en la fosa renal acompañada generalmente de dolot. Se destacan los siguientes hechos:

1. En los 3 nin̄os en que la masa fue el único signo, se pensó lógicamente en tumor maligno $y$ se efectuaron pocos exámenes, para ir precozmente a la exploración quirúrgica, conducta concordante con la gravedad de la sospecha. Por esta razón el diagnóstico de hidatidosis se hizo durante o después de la intervención.

2. Un niño presentaba gran masa en hipocondrio derecho, con una imagen redondeada y calcificada que hizo pensar en quisie hidatídico hepático.

3. El único caso con diagnóstico preoperatorio correcto, confirmado por Pielografía, correspondió a un niño de 4 años, que tenía el antecedente de intervención previa por hidatidosis cerebral y que también mostraba imágenes redondas de quistes en ambos pulmones. 
Tabla No 2

H I D A T I DOSIS DE FOSA RENAL

Hospital Luis Calvo Mackenna $\mathrm{I}-74$ a XI-75

\begin{tabular}{|c|c|c|c|c|c|}
\hline Identific. & Cuadro clinico & Diag. ingreso & Est. radiologico & Tratamiento & Anat. patológica \\
\hline $\begin{array}{l}1 \text { N.V.C. Masc. } \\
4 \text { a. Urbano } \\
\text { Perro }+\end{array}$ & $\begin{array}{l}\text { Oper. VI-74 QH } \\
\text { CEREBRAI, IX-75 } \\
\text { Ncumopat. y MASA } \\
\text { HD y FLANCO }\end{array}$ & $\begin{array}{l}\text { QH RENAL } \\
\text { Hepático } \\
\text { Pulmonar }\end{array}$ & $\begin{array}{l}\text { Hemog.: } 7 \text { Eosin. Pielo: deform, y desplaz. } \\
\text { Hemoaglutin }(+) \text { pielocaliciario }\end{array}$ & QUISTFCTOMIAS C & QH RENAL DERECHO \\
\hline $\begin{array}{l}2 \text { R.B.C. Masc. } \\
5 \text { a. Rural }\end{array}$ & $\begin{array}{l}6 \text { ms. Dolor, De- } \\
\text { caim. y MASA FID. } \\
\text { y FLANCO }\end{array}$ & $\begin{array}{l}\text { TUMOR ABDOMINAL } \\
\text { WIIMS? } \\
\text { NEUROBLASTOMA? }\end{array}$ & $\begin{array}{ll}\text { Hemog.: } 2 \text { Eosin. } & \text { Pielografíg: } \\
\text { Cintigrama: } & \text { Desplazamiento } \\
\text { Riñon reducido } & \text { pielocaliciario } \\
\text { a } 1 / 3 \text { superior } & \end{array}$ & $\begin{array}{l}\text { OUIMIOTERAPIA } \\
\text { NFFRECTOMIA } \\
\text { DERECHA }\end{array}$ & $\begin{array}{l}\text { QH RENAL } \\
\text { Fibrosis cicatricial }\end{array}$ \\
\hline $\begin{array}{l}3 \text { H.Y.L. Masc. } \\
8 \text { a. Urbano }\end{array}$ & $\begin{array}{l}15 \text { ds. decaim. } \\
\text { DOLOR y MASA } \\
\text { FLANCO e HD }\end{array}$ & $\begin{array}{l}\text { TUMOR ABDOMINAL } \\
\text { Linfosarcoma? } \\
\text { Wilms? Neuroblastoma? }\end{array}$ & $\begin{array}{c}\text { Hemog.: } 4 \text { Eosin. Abdominal simple N.E. } \\
\text { Pielo: no se hizo }\end{array}$ & $\begin{array}{l}\text { Nefrectomia } \\
\text { DERECHA }\end{array}$ & $\begin{array}{l}\text { Q.H. hilio renal der. } \\
\text { nefritis intersticial }\end{array}$ \\
\hline $\begin{array}{l}4 \text { H.S.R. Fem, } \\
2 \text { a. Urbano } \\
\text { Perro }+\end{array}$ & $\begin{array}{l}\text { Hepatomegalia y } \\
\text { molestias urinarias } \\
\text { MASA en H.D. }\end{array}$ & QH IIEPATICO & $\begin{array}{r}\text { Hemog.: } 7 \text { Eosin. Abdominal simplc: } \\
\text { Masa } 8 \text { cms. } \\
\text { Calcific. borde infer. }\end{array}$ & QUISTECTOMIA C & Q.H. Pararrenal der. \\
\hline $\begin{array}{l}5 \text { R.G.C. Masc. } \\
14 \text { a. Urbano }\end{array}$ & $\begin{array}{l}5 \mathrm{~ms} \text {. Masa Jumbar } \\
\text { izq. fistulizada } \\
\text { to dias antes ingreso }\end{array}$ & $\begin{array}{l}\text { TUMOR POLO INF. } \\
\text { RINOON IZQ. } \\
\text { Flcgmón perinefrítico }\end{array}$ & Hemog.: 16 Eosin. Piclo directa normal & $\begin{array}{l}\text { VACIAMIENTO } \\
\text { DRENAIE }\end{array}$ & Q.H. Pararrenal izq. \\
\hline
\end{tabular}


La radiología es, sin duda, el examen más útil en el diagnóstico. La radiografía simple mostró calcificación de la imagen redondeada en un caso y la pielografía evidenció deformidad renal (Fig. 1) que sugería masa in- trínseca, pero sin signos característicos que aclararan su naturaleza. La radiología localiza la masa, informa sobre el riñón opuesto, pero no puede descartar la posibilidad de tumor maligno.
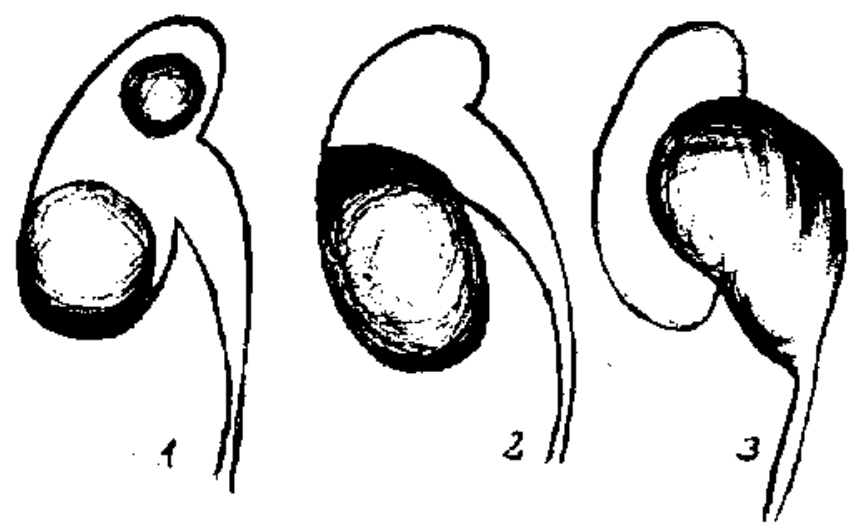
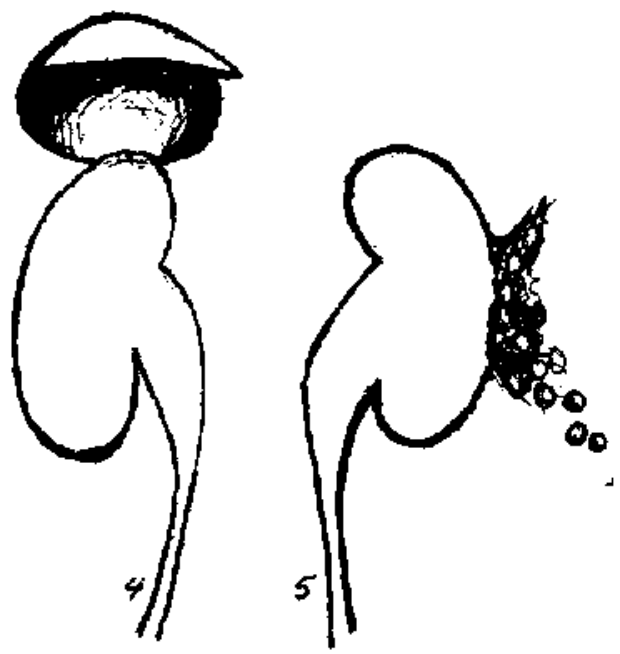

Figura No 1.- Locolización de los quistes hidatídicos renales (5 casos).

\section{TRAT AMIENTO}

La actitud terapéutica fue distinta, atendiendo al diferente diagnóstico preoperatorio:

1. En el caso 1 el diagnóstico preoperatorio fue correcto, por el antecedente de hidatidosis múltiple operada, $y$ la pielografía mostró masa intrarrenal expansiva del polo inferior. Pensando en evitar diseminación, se exploró por lumbotomfa, encontrándose 2 quistes, en los polos renales.

2. Tres pacientes fueron laparotomizados por masa abdominal, en 2 se hizo la nefrectomía (casos 2 y 3), pensando en tumor maligno. En uno el quiste era intrarrenal $y$ en el otro del hilio. No se hizo punción o biopsia, por la grave consecuencia que ello significa, si se trata de tumor de Wilms. El cuarto caso resultó ser $Q H$ pararrenal y se practicó quistcctomía por la buena individualización operatoría.
3. Un niño portador de tumor y fístula lumbar (caso 5), se somtetio a raspaje quirúrgico con diagnóstico de Flegmón perinefrítico y el curetaje obtuvo numerosas vesículas hijas. La complicación de infección y supuración fistulizada, al destruir el quiste evitó la nefrectomía.

\section{COMENTARIO}

La ventaja de hacer el diagnóstico preoperatorio de quiste hidatídico, se traduce en el criterio conservador correspondiente, que evita la nefrectomia.

El compromiso del riñon fue primario en 4 casos y en uno fue secundario a diseminación o hidatidosis múltiple.

La presencia de masa palpable fue común a todos los casos. La eosinofilia fue significativa en 3 casos. Otros hechos importantes son los siguientes:

Las pruebas inmunobiologicas son poco específicas cuando se refieren a riñon (1).

Prácticamente no hay alteraciones urinarias ni compromiso de la función renal. 
La hidatiduría es poco frecuente.

Estos hechos explican la dificultad para Hegar al diagnóstico preoperatorio.

Creemos que el tratamiento del quiste hidatídico de fosa renal, con diagnóstico confirmado, es la punción y vaciamiento del quiste, operación sencilla que soluciona una afección de difícil diagnóstico.

Pensamos que el lento crecimiento del quiste permite adaptarse a la distorsión manteniendo una buena eliminación renal, aun en quistes de gran tamaño o múltiples. Esto puede atribuirse a la localización habitualmente periférica. (1)

\section{RESUMEN}

Se analiza el diagnóstico y tratamiento de 5 casos de hidatidosis de fosa renal, tratados en un periodo de 21 meses en el Servicio de Cirugía del Hospital de Niños Calvo Mackenna, 2 fueron nefrectomizados y 3 tratados con cirugía conservadora.

La hidatidosis renal es poco frecuente y se manifiesta como masa tumoral de flanco que sugiere neoplasia, de la cual debe diferenciarse.

La radiología contribuye a localizar la masa, pero no muestra elementos típicos que oriente a etiología hidatídica.

No suele dar signos urinarios ni reacción inmunológica.

El diagnóstico preciso es đifícil y sólo se logró en uno de nuestros pacientes por presentar hidatidosis múltiple.
Si se hace el diagnóstico correcto de esta afección, el tratamiento quirúrgico debe ser conservador.

\section{SUMMARY}

5 patients with renal or pararenal hydatidosis where treated during the last 21 months at the surgical departament of the Catvo Mackenna Children's Hospital, 2 where neplarectomized and the others 3 had a conservative surgical treattnent.

Renal Hidatidosis is rarely suspected end presents itself as a flank tender mass wich usually suggest a malignancy.

$\mathrm{X}$ ray examination has no pathognomonic features but is usefull in localizing the mass and in showing the contralateral kidney's conditions.

No urinary signs are to be expected and inmunological test are inconsistent.

Correct preoperative diagnosis is diffictlt if a disemination is not presented.

The elective treatment is conservative, consisting in the cystectomy.

\section{REFERENCIAS}

t Calderón, C. y A. Ath́as. Rev. Méd. Chile. 101: 955-960, 1973.

2. Cecil $R$. and. Loeb R. Tratado de Medicina Interna. Edit. Interamericana, 1962.

3. Rubio, M. Hering and Ross, G. Rev. Chil. Pediat. 4: 276-287, 1963.

4. Neira M. et al. Bol. Chil. Parasitología 23 (1.2): $65.67,1968$.

5. Carcassonme $M$. et al. Progress in pediatric Surgery. vol. 5: 1-35, 1973. 